\section{Vietnam Journal of Agricultural Sciences}

\title{
Greenhouse Gas Emissions from Piggery and Biogas Digesters in the North of Vietnam
}

\author{
Pham Van Dung ${ }^{1}$, Duong Cong Hoan ${ }^{2}$, Jacobo Arango ${ }^{3}$, Tran \\ Dai Nghia ${ }^{4}$, Nguyen Tri Kien ${ }^{1}$, Ashly Arevalo ${ }^{3}$ \& Sabine \\ Douxchamps ${ }^{1}$
}

\author{
${ }^{1}$ Alliance of Bioversity International and International Center for Tropical Agriculture \\ (CIAT), Hanoi 143330, Vietnam \\ ${ }^{2}$ Department of Livestock Production, Ministry of Agriculture and Rural Development, \\ Hanoi 124332, Vietnam \\ ${ }^{3}$ Alliance of Bioversity International and International Center for Tropical Agriculture (CIAT), \\ Apartado Aéreo 6713, Cali, Colombia \\ ${ }^{4}$ Institute of Policy and Strategy for Agriculture and Rural Development (IPSARD), Hanoi \\ 124332, Vietnam
}

\begin{abstract}
Increases in pig farm densities have caused great pressures on waste management systems and produce massive manure and urine quantities in Vietnam. This study aimed to identify the role and contributions of biogas digesters to better manage the sources of greenhouse gas (GHG) emissions from pig wastes for different types of pig farms in the north of Vietnam. Four provinces, namely Thanh Hoa, Phu Tho, Thai Binh, and Vinh Phuc, were identified. A total of 24 farms were purposively selected including 16 small-size farms and 8 larger-size farms. The findings showed that GHG emissions from small-size farms $\left(154.8 \mathrm{t} \mathrm{CO}_{2}\right.$-eq. $\left.\mathrm{yr}^{-1}\right)$ did not significantly differ from the amounts measured in larger-size farms $\left(139.1 \mathrm{t} \mathrm{CO}_{2-}\right.$ eq. $\mathrm{yr}^{-1}$ ) in the four surveyed provinces. The sampling position did not significantly affect the GHG emission rates, with $173.9 \mathrm{t} \mathrm{CO}_{2-}$ eq. $\mathrm{yr}^{-1}$ inside piggeries and $120.8 \mathrm{t} \mathrm{CO}_{2}$-eq. $\mathrm{yr}^{-1}$ outside the outlet of the biogas digesters ( $p$-value $=0.09) . \mathrm{N}_{2} \mathrm{O}$ emissions require further measurements at different farm sizes and sites. These results confirmed that the pig waste management of biogas digesters for both small-size and larger-size pig farms is not completely efficient and that efforts need to be invested in to mitigate GHG emissions in pig production. Reducing pig density per piggery is highly recommended. The application of other alternative aerobic or anaerobic digestion technologies like vermicompost, effective microorganisms, and composting should also be encouraged and promoted.
\end{abstract}

Received: August 3, 2020 Accepted: January 20, 2021

Correspondence to phamdung86@gmail.com

\section{Keywords}

Biogas digester, emission rate, greenhouse gas, pig production, Northern Vietnam 


\section{Introduction}

Livestock is one of the fastest-growing subsectors of agriculture in Vietnam. In the past, livestock raising activities based on feeding agricultural by-products were popular in smallholder farms in all agro-ecological zones. However, these have been sharply shifting from small-size to larger-size or industrial levels during the last decade. Under the orientations of the livestock production development strategies of the Ministry of Agriculture and Rural Development of Vietnam (MARD) from 2008 to 2020, the herd size and growth rate of livestock in general has quickly advanced towards industrial productions in areas where appropriate conditions for livestock raising, such as types of animals, housing systems, location, farm size, land for waste disposal, and policy support, are met. Consequently, animal populations have remarkably increased, especially pig herds, which reached 27.4 million heads in 2017 at an annual growth rate of $2.3 \%$ between 2013 and 2017. More than 14,858 intensive pig farms at different production levels are nationally listed (General Statistical Office of Vietnam, 2019). Two-thirds of the intensive farms are in the Red River Delta and Northern provinces and the rest are in the South.

Manure management is one of the mitigation components of agriculture under the Nationally Determined Contribution (NDC)'s framework that the Vietnam government is undertaking to implement during the period of 2020-2030.

To achieve its mitigation goals, the Vietnamese government has planned specific actions to develop an additional 300,000 biogas digesters, which are expected to mitigate 1.92 million tons of $\mathrm{CO}_{2}$-equivalent $\left(\mathrm{CO}_{2}\right.$-eq), and improve animal feeds, which are anticipated to mitigate 0.13 million tons of $\mathrm{CO}_{2}$-eq. These plans are essential contributions to the Vietnamese government's policy implications and international commitments on climate change prevention, global warming, and GHG mitigations. Previous reports have shown that manure management practices contributed to $15.1 \%$ of the total agricultural emissions between 1992 and 2012 (Misselbrook et al., 1996; USAID, 2012). It is predicted that the amount of GHG emissions will continue to rise in the coming years.

However, livestock population intensification is linked to an increase in waste production, reaching 26.5 million tons and 33.7 million $\mathrm{m}^{3}$ for solid and liquid wastes, respectively (Nguyen Van Bo, 2017). Waste disposal is not yet organized, with an estimation of about $60 \%$ of wastes treated and used effectively through technologies as such biogas digesters and composting (Ginting et al., 2003; (Nguyen Van Bo, 2017; Yaman, 2020; Yaman et al., 2020). The rest remains untreated and is directly released into the environment. The dumping and inappropriate management of wastes before discharging them into the surrounding environment have caused varying degrees of water, soil, and air pollution, and epidemic diseases to human and animal habitats. These not only cause losses from recycling wastes for use as fertilizers and biogas, but also increase GHG emissions such as carbon dioxide $\left(\mathrm{CO}_{2}\right)$, methane $\left(\mathrm{CH}_{4}\right)$, and nitrous oxide $\left(\mathrm{N}_{2} \mathrm{O}\right)$.

There is potential to switch from waste to energy and contribute to economic, social, and environmental benefits (Aracil et al., 2018; Y1lmaz \& Abdulvahitoğlu, 2019; Yaman et al., 2019; Yaman et al., 2020). Biogas digesters have been known for their multi-purpose nature, treating waste and producing energy at the same time. Biogas and digestates produced through the anaerobic digestion of organic matter inside the digester are important products to feed trees and improve environmental issues. Biogas could also replace other energy sources such as fossil fuels, firewood, and agriculture residues that are commonly used for households in rural areas (Müller, 2007; Amigun et al., 2008; Adu-Gyamfi et al., 2012; Molino et al., 2013; Hinh, 2017; Chen, 2018). Recently, about 500,000 biogas digesters were built, mainly in the north of Vietnam where the density of pig production is the largest. Of these, 83.3 thousand digesters are now used in the northern midlands and mountainous areas, 123.8 thousand digesters in the northern central and coastal areas, and 154.0 thousand digesters in the Red River Delta ( Tong Xuan Chinh, 2017; Hinh, 2017). However, recent 
findings showed that the quality of manure decomposition of these systems is limited, with animal density causing high pressure on the biogas digesters' volume, as their size is not big enough for treatments anymore. In addition, GHG emissions from the biogas digesters were not quantified, neither for small-size nor for larger-size pig production systems. Therefore, this study aimed to quantify the GHG emissions from biogas digesters in different types of pig production systems and at different locations of piggery.

\section{Methodology}

\section{Description of study sites}

This study was carried out in four districts in four provinces: Thanh Hoa (TH), Phu Tho (PT), Thai Binh (TB), and Vinh Phuc (VP). These provinces represent the areas of the North of Vietnam where the largest pig populations and densities are observed per farm. A nonprobability convenience sampling method based on suggestions from the Department of Livestock Production, Ministry of Agriculture and Rural Development Vietnam was applied to select the pig farms. Due to constraints of financial and various resources, the study size was calculated to account for one percent out of the 2,674 livestock farms in the four provinces in 2017 (General Statistical Office of Vietnam, 2018). A total of 24 farms were selected, among which, 16 were small-size farms and 8 were larger-size farms corresponding to the different levels of pig herd size in the selected provinces. Six pig farms were randomly sampled in each district of the four provinces, and were named as the TH farms, TB farms, VP farms, and PT farms according to the initials of the provinces. The farm category was defined according to the number of fattened pig heads per farm. Farms fell in the larger-size category when the total pig heads were more than 10 pigs per farm. The farms that had less than 10 pigs per farm were as classified as small-size farms. Pig farms of each type were characterized by the same raising practices. Concentrated feed was the main input for both farm sizes, while a small quantity of agricultural by-products was also used in the small-size pig farms. No use of antibiotics was found in the selected farms. The study was done on three types of biogas digesters, specifically the KT1, KT2, and composite plastic structures. These biogas digesters were usually built underground beneath the piggery. The digesters were filled through the inlet tank and the inlet pipe. The produced biogas then accumulated at the upper part of the digesters.

\section{Description of the static chamber operation}

The static chamber system has been applied extensively to measure rates of trace gas emission sources (Hutchinson \& Mosier, 1981; Hutchinson \& Livingston, 1993; Kusa et al., 2008), and allows the detection of gases emitted from a surface of a volatile solid within a known volume during a known period of time. In this study, a static chamber system was designed following the GHG emission measurement protocol that was developed by Ashly et al. (2018). This system was connected to a Gasmet DX-4040 Fourier Transform Infrared Multicomponent Trace Gas Analyzer. The chamber was programmed to be closed for fifteen minutes (one observation), with three observations performed in one hour. The total number of observations was 72 . The FTIR gas analyzer measured the main greenhouse gases at low concentrations in parts per million units per second (ppm. $\mathrm{s}^{-1}$ ) including $\mathrm{CO}_{2}, \mathrm{CH}_{4}, \mathrm{~N}_{2} \mathrm{O}$, and water vapor. The response time of the analyzer was 20 seconds for one reading and the flow speed of the sample pump was 1.5 liters $\mathrm{min}^{-1}$. The gas analyzer was calibrated with pure nitrogen $\mathrm{N}_{2}$ (2 liters $\mathrm{min}^{-1}$ ) prior to each measurement. The chamber was inserted into the base and sealed with a black rubber ring while the base was inserted into the sample and sealed with water.

\section{Gas sampling procedure}

Gases were sampled from October 1 to November 11, 2018 from pig manure collected at two locations per farm, inside the piggery and outside the biogas digester. Inside the piggery, a composite sample was obtained from fresh solid manure or slurry taken at two random positions, while at the outlet of the biogas digester, one 
sample of digested wastes was taken directly. Pig manure was then kept on white plastic plates (radius $=9.25 \mathrm{~cm}$ ). The plates with pig manure were then weighed to note the initial mass using an electronic scale (Model-HY K17, 5kg). Fresh solid pig manure was sampled in the same locations, and weighted and dried in the microwave until the mass was stable. The dry matter content in the samples was recorded to calculate the equivalent rate of water and pig waste in each type of farm size. Parameters were recorded at the time of measurement for each sampling duration.

\section{Calculation of GHG emission fluxes}

Emission fluxes were computed from the change in gas concentration with time. There are two main approaches of GHGs emission rate calculations based on the static chamber method, namely the linear and non-linear models (Anthony et al., 1995; Phillips et al., 2000). For the linear model, the gas concentration within the container headspace increase linearly with time. As such, fluxes are calculated from the slope of the linear regression between gas concentrations versus time (Whalen \& Reeburgh, 2001). The equation is described as follows:

$$
\mathrm{F}=\frac{\Delta \mathrm{C}}{\Delta \mathrm{t}} \frac{\mathrm{P}}{\mathrm{P}_{0}} \frac{273.15}{\mathrm{~T}_{\text {Kelvin }}} \frac{\mathrm{v}}{\mathrm{A}} \frac{\mathrm{M}}{V_{S}}
$$

where, $\mathrm{F}$ is the flux rate (mass unit. $\mathrm{m}^{-2} \cdot \mathrm{h}^{-1}$ ), $\mathrm{P}$ is the measured ambient pressure (mbar), $\mathrm{P}_{0}$ is the standard pressure (1013.25 mbar), $\mathrm{v}$ is the total system volume $(\mathrm{L}), \mathrm{V}$ is the volume occupied by $1 \mathrm{~mol}$ of the gas at standard temperature and pressure (STP) $(0.024 \mathrm{~m} 3$, or $22.4 \mathrm{~L}$ ) calculated by the equation:

$$
\sum V=V_{\text {headspace }}+V_{\text {tubing }}+V_{\text {cell of gas analyzer }}
$$

where, $\mathrm{A}$ is surface area of the chamber over the emission source $\left(\mathrm{m}^{2}\right), \mathrm{T}$ is the ambient temperature in degrees Celsius $\left({ }^{\circ} \mathrm{C}\right), \mathrm{T}_{\text {Kelvin }}$ is the temperature $\mathrm{T}$ in Kelvin $(\mathrm{K})=\left(273.15+\mathrm{T}_{\mathrm{c}}\right)$, $\Delta \mathrm{C} / \Delta \mathrm{t}$ is the change in concentration in time interval $t$ or the slope of the gas concentration curve $\left(\mathrm{ppm} \cdot \mathrm{s}^{-1}\right)$, and $\mathrm{M}$ is the molecular weight $\left(\mathrm{g} \mathrm{mol}^{-1}\right)$.
The GHG fluxes data were first tested for normality. The GHG emissions rates were determined from linear regressions, using the goodness of fit and the significance level for model selection. The significance of the differences between emission fluxes in the different piggeries was tested by a one-way ANOVA analysis. These statistical analyses were performed using the stats package in the $\mathrm{R}$ software, version 3.5.1. As $\mathrm{N}_{2} \mathrm{O}$ gas fluxes were nonlinearly distributed, the concentrations $\mathrm{C}_{0}$, $\mathrm{C}_{1}, \mathrm{C}_{2}$, corresponding to the time intervals of 0 , 5 , and $10 \mathrm{~m}$, were used for calculations.

\section{Results}

Descriptive characteristics of the pig production systems in the surveyed locations

The characteristics of the piggery structures and pig populations are shown in Table 1. The TB farms had the largest number of fattened pigs and sows while the number of piglets was the greatest in the $\mathrm{TH}$ farms. The average area of piggeries in the TB and TH farms was two times larger than the one of the farms from the other two provinces. The largest average volume $\left(\mathrm{m}^{3}\right)$ of the biogas digesters was found in the $\mathrm{TH}$ farms. Feces and urine were gathered in the same inlets of the biogas digesters without separation. The period of manure storage inside a biogas digester was usually one year. However, the biogas digester sizes, commonly ranging from 10.8 to $13.5 \mathrm{~m}^{3}$, and the treatment duration were not large or long enough to digest and decompose the amount of produced manure. The digested wastes, after being removed from the biogas digesters and discharged into the surrounding environment of the piggery and pig raiser's residences, still provided odour emissions and polluted the water and soil.

\section{Greenhouse gas emissions from piggery and manure management}

Table 2 presents the GHG $\left(\mathrm{CO}_{2}, \mathrm{CH}_{4}, \mathrm{~N}_{2} \mathrm{O}\right)$ concentrations (ppm) from the pig farms in the surveyed provinces. Notably, the concentration of $\mathrm{CO}_{2}$ was the main contributor to the increased emissions, followed by the $\mathrm{CH}_{4}$ concentration. The concentrations of these gases were measured 
Table 1. Average pig production characteristics by province and by farm size

\begin{tabular}{cccccccccc}
\hline \multirow{2}{*}{ Indicators (units) } & \multicolumn{2}{c}{ PT farms } & \multicolumn{2}{c}{ TB farms } & \multicolumn{2}{c}{ TH farms } & \multicolumn{2}{c}{ VP farms } \\
\cline { 2 - 9 } & Small & Large & Small & Large & Small & Large & Small & Large \\
\hline Sample size (farm) & 4 & 2 & 4 & 2 & 4 & 2 & 4 & 2 \\
Number of sows (head) & 2.2 & 0.0 & 3.7 & 5.0 & 1.3 & 2.8 & 2.2 & 2.6 \\
Number of fattened pigs (head) & 7.8 & 25.5 & 8.6 & 52.5 & 6.7 & 41.4 & 6.5 & 23.0 \\
Number of piglets (head) & 10.3 & 20.4 & 14.3 & 24.0 & 18.1 & 72.5 & 8.8 & 30.0 \\
Piggery's area (m $\left.{ }^{2}\right)$ & 35.6 & 84.5 & 51 & 136.3 & 57.8 & 640.4 & 68 & 137.7 \\
Volume of biogas digesters $\left(\mathrm{m}^{3}\right)$ & 8.4 & 14.5 & 9.0 & 13.5 & 9.0 & 16.0 & 8.5 & 14.3 \\
\hline
\end{tabular}

Note: $P T=$ Phu Tho; $T B=$ Thai Binh; $T H=$ Thanh Hoa; VP = Vinh Phuc

Table 2. Greenhouse gas concentrations from the 24 pig farms in the four study provinces

\begin{tabular}{ccccccccc}
\hline & \multicolumn{2}{c}{ PT farms } & \multicolumn{2}{c}{ TB farms } & \multicolumn{2}{c}{ TH farms } & \multicolumn{2}{c}{ VP farms } \\
\cline { 2 - 9 } Concentration (ppm) & Mean (SD) & $\begin{array}{c}\text { R- } \\
\text { squared }\end{array}$ & Mean (SD) & $\begin{array}{c}\text { R- } \\
\text { squared }\end{array}$ & Mean (SD) & $\begin{array}{c}\text { R- } \\
\text { squared }\end{array}$ & Mean (SD) & $\begin{array}{c}\text { R- } \\
\text { squared }\end{array}$ \\
\hline $\mathrm{CO}_{2}$ & $1162(428)$ & $0.994^{* * *}$ & $1078(403)$ & $0.861^{* * *}$ & $1259(311)$ & $0.928^{* * *}$ & $1257(679)$ & $0.848^{* * *}$ \\
$\mathrm{CH}_{4}$ & $33.3(25.1)$ & $0.995^{* * *}$ & $28.7(22.8)$ & $0.844^{* * *}$ & $47.6(25.5)$ & $0.862^{* * *}$ & $45.6(31.3)$ & $0.845^{* * *}$ \\
$\mathrm{~N}_{2} \mathrm{O}$ & $0.5(0.3)$ & $0.658^{* *}$ & $0.5(0.1)$ & $0.703^{* * *}$ & $0.3(0.07)$ & 0.459 & $0.4(0.03)$ & $0.471^{* *}$ \\
\hline
\end{tabular}

Note: SD means standard deviation; ${ }^{* * *},{ }^{* *}$ means significant difference at $1 \%$ and $5 \%$ level.

at higher levels in Thanh Hoa and Vinh Phuc provinces than in the remaining provinces. The ANOVA indicated that the GHG concentrations had a normal distribution and did not differ significantly among the selected provinces for both $\mathrm{CO}_{2}(\mathrm{~F}=1.79 ; \mathrm{P}=0.61)$ and $\mathrm{CH}_{4}(\mathrm{~F}=1.47$; $\mathrm{P}=0.68$ ). The concentrations of $\mathrm{CO}_{2}$ and $\mathrm{CH}_{4}$ increased linearly over time within the chamber headspaces. The regression R-squared values of these two gases were significant in all the surveyed sites.

The regression $\mathrm{R}$-squared values were lower for $\mathrm{N}_{2} \mathrm{O}$ because the curve of this gas concentration increase was non-linear (quadratic, exponential). Therefore, the equation for $\mathrm{F}$ as described above was applied for $\mathrm{CO}_{2}$ and $\mathrm{CH}_{4}$ while the calculation of $\mathrm{N}_{2} \mathrm{O}$ emissions was the concentration at specific time intervals $(0,5$, and 10 minutes). The $\mathrm{N}_{2} \mathrm{O}$ concentrations among the samples increased in the PT and TB farms and decreased in the TH and VP farms.

The relationship between the intensification of GHG emissions $\left(\mathrm{CO}_{2}\right.$ and $\mathrm{CH}_{4}$; tons. $\left.\mathrm{yr}^{-1}\right)$ from pig manure and the number of pig heads and feed intake is shown in Table 3. Remarkably, $\mathrm{CO}_{2}$ emissions were by far the largest contributor to
GHG emissions in terms of mass with a wide variation between farms. The final value was converted to the $\mathrm{CO}_{2}$-eq, and the contribution from $\mathrm{CH}_{4}$ emissions played an important role. The emission rates did not vary significantly between the sampling locations, whether inside the piggery or outside the outlet of the biogas digester at the sampling points (Figure 1), although the emissions of $\mathrm{CO}_{2}$ and $\mathrm{CH}_{4}$ were insignificantly higher inside compared to outside the outlet of the digester tank.

In order to detect the effect of feed components on emissions, the relationship between GHG emissions rates and the dry matter content of the pig manure is demonstrated in Figure 2. The water-dry matter ratio for solid manure was $4: 1$. The average temperature and humidity conditions at the sampling sites were $24.75^{\circ} \mathrm{C}$ and $80.15 \%$, respectively. Emission rates tended to increase as the dry matter content in the manure increased. However, the variation needs to be reinforced from further studies. The emission rates of $\mathrm{CO}_{2}$ and $\mathrm{N}_{2} \mathrm{O}$ showed higher variation in the small-size farms than in the larger-size farms (Figure 3). The $\mathrm{CH}_{4}$ emission 
Table 3. Greenhouse gas emissions from pig manure by pig head and feed inputs

\begin{tabular}{|c|c|c|c|c|}
\hline \multirow{2}{*}{$\begin{array}{l}\text { GHG emission } \\
\left.\text { (tons } \mathrm{yr}^{-1}\right)\end{array}$} & \multicolumn{2}{|c|}{ Total number of pigs (head) } & \multicolumn{2}{|c|}{ Feed input (kg day $\left.{ }^{-1}\right)$} \\
\hline & Mean & SD & Mean & SD \\
\hline $\mathrm{CO}_{2}$ & 8.04 & 10.9 & 5.61 & 7.71 \\
\hline $\mathrm{CH}_{4}$ & 0.13 & 0.19 & 0.09 & 0.13 \\
\hline $\mathrm{N}_{2} \mathrm{O}$ & 0.0002 & 0.0012 & 0.0001 & 0.0008 \\
\hline $\mathrm{CO}_{2}$-eq (tons $\mathrm{yr}^{-1}$ ) & 11.4 & & 7.9 & \\
\hline
\end{tabular}

Note: SD means standard deviation

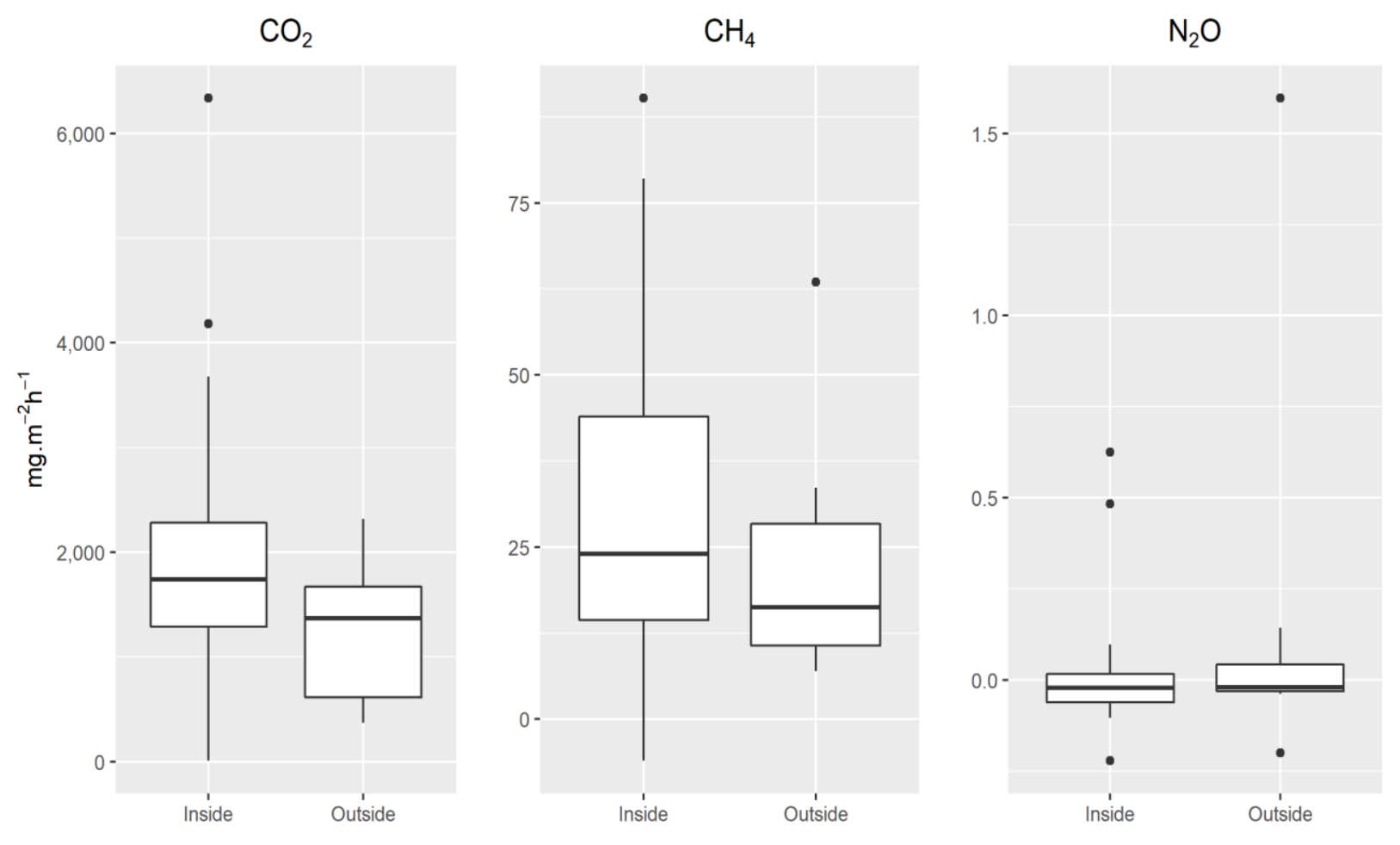

Figure 1. Emission rate of pig manure inside the piggery and outside storage

rates were significantly greater in the larger-size farms compared to the small-size farms.

\section{Discussion}

\section{Pig farm location and stall structure characteristics affecting the GHG emissions}

Although the structure of the pig house does not directly affect GHG emissions, it determines how manure is handled, stored, processed, and used. For the pig house location, this study found that most of the small-size farmers built their pig houses near or inside their residential area at a very close distance (around 17 to $67 \mathrm{~m}$ ). Piggeries were placed within farmers' residences. This could be explained because pig raising conditions and infrastructures were similar in all these provinces. This means that the capacity of the biogas digesters in the piggeries to decompose organic matter and digest pig manure was not completely efficient. Otherwise, the biases of sampling selection, the standards of pig farm classification based on Vietnamese regulations, and the heterogeneity among the selected sites were factors that could explain the differences in GHG emissions between these types of pig farms.

Unlike the larger-size pig farms, which were required to arrange outside far away from the community's residences, the location of small- 
size pig farms in residential areas was commonly seen. This made it more convenient to clean and take care of the pig herds. However, there were risks of water and air contamination, as well as epidemic diseases. The exchange between GHG and odor emissions of excreta indoor and the atmosphere outdoor was restrained by the surrounding infrastructures. In conditions of high temperature, the emissions were stronger, especially for $\mathrm{CO}_{2}$ and $\mathrm{CH}_{4}$. These results agreed
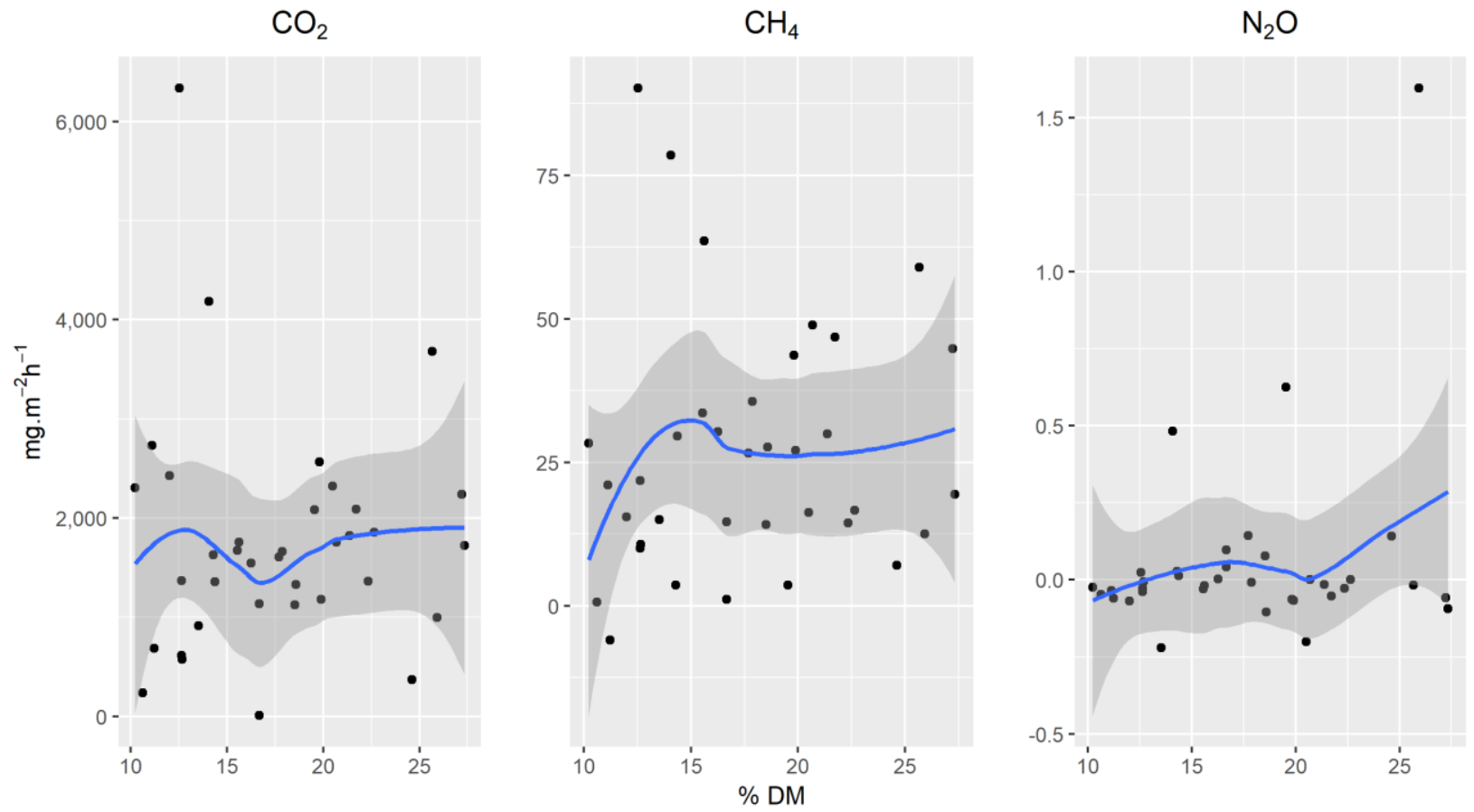

Figure 2. Relationship between the GHG emission rate and dry matter in the pig manure
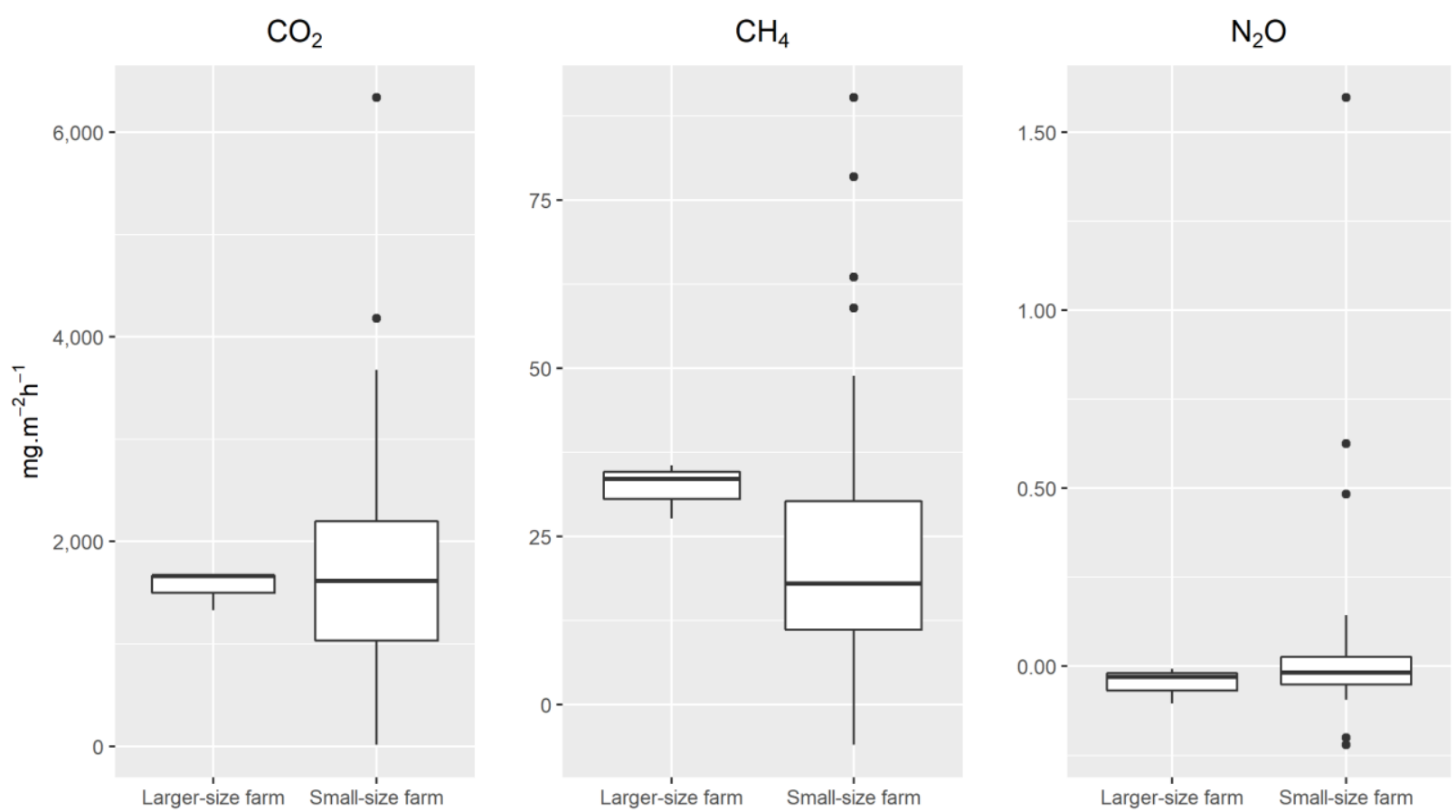

Figure 3. Emission rate of pig manure by farm size 
with the previous findings of Misselbrook \& Powell (2005), Ngwabie et al. (2011), and Korkut et al. (2018). For this reason, the manure management method using biogas digesters should be appropriate to deploy under the floor or outside near the pig house. In addition, the pig house type and structure played an important role in $\mathrm{CO}_{2}, \mathrm{CH}_{4}$, and $\mathrm{N}_{2} \mathrm{O}$ emission intensification. The most frequent problems with structural components were related to the floor characteristics. The natural ventilation pig house structure and slatted floor were popular for both larger-size and small-size farms in the study sites. Housing systems with slatted floors were realized to be more likely to accumulate manure in liquid or slurry form. Depending on the floor type, how to design the pig house could increase or decrease GHG emissions. Different types of floors can have varying effects on GHG emissions. The effect of slatted floor areas on GHG emissions has also been shown to have conflicting results, especially $\mathrm{CH} 4$ and $\mathrm{N} 2 \mathrm{O}$ emissions (Fitamant et al., 1999; Philippe et al., 2007; Guingand et al., 2010; Philippe et al., 2012; Philippe et al., 2014). Pig houses with fully slatted floor systems were observed to reduce $\mathrm{CO} 2$ production by $7-13 \%$ (Sun et al., 2008; Guingand et al., 2010; Sun et al., 2010). In comparison, bedded systems combine a wide range of raising techniques that impact the level of emissions. Bedded floor systems are usually associated with reduced $\mathrm{CH} 4$ emissions, but increased $\mathrm{CO} 2$ and $\mathrm{N} 2 \mathrm{O}$ emissions. Therefore, the selection of suitable materials is significant not only for the raising conditions of the pigs and benefits of production costs, but also practical issues such as manure storage and drainage. Together with the pig house site arrangement, the floor type and structure system also determined the feasibility of using anaerobic digestion or composting to treat the manure with its associated effects on GHG emissions. However, more evidence related to different floor types is needed to confirm their effects on gas emissions in pig houses in the North.

\section{Biogas digester volume and design affecting GHG emissions}

The biogas digester volume calculation depends on the volume of manure produced. In the case of Northern Vietnam, small-size biogas digesters are still predominant, with the most common sizes being from $6 \mathrm{~m}^{3}$ to $12 \mathrm{~m}^{3}$ (Roubík et al., 2016). However, results from this study showed that an average quantity of manure from 5 sows, 58 market pigs, and 59 piglets per farm produced $2.7 \mathrm{~kg}$ per day, which was a lot for the average size of the biogas digesters $\left(12.6 \mathrm{~m}^{3}\right)$ to handle pig wastes. Another key finding was that there was no significant difference between the amounts of GHG emission produced before and after the use of the biogas digesters, showing the inefficiency of the process. This leads to a lack of organic matter in the digestate, usually caused by the use of excessively high water per manure ratios (Tran et al., 2011; Thu et al., 2012; Roubík et al., 2016). The imbalance between the manure and water ratios promoted the digester filling faster and reduced the retention time of the feces. Thu et al. (2012) showed that $55-60 \%$ of the digesters had a retention time between 1 and 20 days. In these biogas digesters the organic matter was inefficiently transformed to biogas. This means that the waste decomposition process continued to happen after being discharged into the environment (Yaman, 2020).

\section{Gap of knowledge for future studies}

This case study has shown that waste management and treatment processes were only moderately effective in mitigating GHG emissions and improving fertilizer utilization, as the level of GHG emissions before and after the use of biogas digesters remained high. Several gaps in knowledge could be addressed by future studies. The study initially evaluated the efficiency of GHG emission reduction in biogas digester systems. Comparisons with other waste management technologies are needed, such as composting technology, solid and liquid manure separation technology, EM technology, etc. This knowledge will be helpful to target interventions for different manure management technologies and prioritize them for government programs. Care should be taken when extrapolating research results to other regions, and more 
assessments are needed in larger-size and smallsize pig farms in different geographical zones to consolidate findings of emission levels at different production scales. Feed sources play an important role in total GHG emitted. Most households currently use concentrated feed, and the comparative emissions following feeding with alternative products should be investigated.

This study analyzed emissions at the time of sampling, but did not evaluate emissions over a longer time period, especially changes in seasonal emission rates. Future studies could focus on the impact of seasonal environmental changes, such as the fluctuation of temperature and humidity, on emission rates over time. These results were restricted to specify which type of pig (market pig, sow, and piglet) had high GHG emission rates per pig head. Similarly, the results did not identify GHG emission rates for the specific type of feed input. Further research is needed to provide additional data on GHG emission and feed intakes to confirm these results.

\section{Conclusions}

Overall, the consequences of this inefficient process were poor GHG emissions mitigation, the lack of organic matter in the digestates, poor quality of biogas, spreading smells of biogas, and loss of nutrients to the environments. The study confirmed that the biogas digesters were overloaded and the quality of manure decomposition was not optimal. The GHG emission amounts $\left(\mathrm{tCO}_{2}\right.$-eq. $\left.\mathrm{yr}^{-1}\right)$ from pig wastes inside and outside of the biogas digesters had great potential to cause greenhouse effects and global warming. However, the GHGs emission rate did not significantly differ between the small-size and larger-size farms in the four surveyed provinces. Sampling position (between inside piggeries and outside the outlet of the biogas digesters) did not significantly affect the GHG emission rate. These results confirmed that the pig waste management of biogas digester systems for both small-size and larger-size pig farms was not efficient and that efforts need to be invested in to mitigate GHG emissions in pig production. This case study suggested that adjustments in pig population numbers and the density of pig heads per piggery floor area unit during a pig production cycle are highly recommended. Modifications to the biogas digester structure are also necessary to separate solid pig manure and urine. Otherwise, the application of other alternative aerobic or anaerobic digestion technologies like vermicompost, effective microorganisms, and compost should also be encouraged and promoted when economic, income, and environmental benefits are met. Biogas digesters in pig production have a significant role to play in the Vietnam government's mitigation strategies, as well as from the perspective of biosafety and animal husbandry policies.

\section{Acknowledgments}

The authors would like to gratefully acknowledge anonymous local supporters, the People's Committees, and the Department of Agriculture and Rural Development of the surveyed provinces for approving the interviews and arranging the site visits. Special appreciation and thanks also to the farmers in the visited sites for their invaluable contributions and openness in sharing with us their experiences and insights. This study was funded by the Livestock and Environment flagship of the CGIAR Research Program on Livestock, which is carried out with support from CGIAR Fund Donors and bilateral funding agreements.

\section{References}

Adu-Gyamfi N., Ravella S. R. \& Hobbs P. J. (2012). Optimizing anaerobic digestion by selection of the immobilizing surface for enhanced methane production. Bioresource Technology. 120: 248-255. DOI: 10.1016/j.biortech.2012.06.042.

Amigun B., Sigamoney R. \& von Blottnitz H. (2008). Commercialisation of biofuel industry in Africa: a review. Renewable and Sustainable Energy Reviews. 12(3): 690-711. DOI: 10.1016/j.rser.2006.10.019.

Anthony W., Hutchinson G. \& Livingston G. (1995). Chamber measurement of soil-atmosphere gas exchange: Linear vs. diffusion-based flux models. Soil Science Society of America Journal. 59(5): 1308-1310. DOI: 10.2136/sssaj1995.03615995005900050015x.

Aracil C., Haro P., Fuentes-Cano D., \& Gómez-Barea A. (2018). Implementation of waste-to-energy options in landfill-dominated countries: Economic evaluation and GHG impact. Waste Management. 76: 443-456. DOI: 10.1016/j.wasman.2018.03.039. 
Ashly A., Dung V. P., Douxchamps S. \& Jacobo A. (2018). Protocols of measuring greenhouse gas emissions from soil and other sources with Gasmet gas analyzer DX4040 application. Hanoi, Vietnam.

Chen Y. C. (2018). Evaluating greenhouse gas emissions and energy recovery from municipal and industrial solid waste using waste-to-energy technology. Journal of Cleaner Production. 192: 262-269. DOI: 10.1016/j.jclepro.2018.04.260.

Fitamant D., Quillien J., Callarec J., Morvan J., Lemasle M. \& Laplanche A. (1999). Nitrogen distribution and net flow in the form of gas and liquid from a piggery. Journées Rech. Porcine. 31: 99-104.

General Statistical Office of Vietnam (2016). Rural and agricultural census [Online]. Retrieved from https://www.gso.gov.vn/default.aspx?tabid=512andid mid=5andItemID=18282 on November 5, 2018 (in Vietnamese).

General Statistics Office of Vietnam (2018). Agriculture, Forestry and Fishing [Online]. Retrieved from https://www.gso.gov.vn/default_en.aspx?tabid=778 on November 25, 2018. (In Vietnamese)

General Statistical Office of Vietnam (2019). Rural and agricultural census [Online]. Retrieved from https://www.gso.gov.vn/default.aspx?tabid=512andid mid=5andItemID $=18282$ on November 5, 2019. (In Vietnamese)

Ginting D., Kessavalou A., Eghball B. \& Doran J. W. (2003). Greenhouse gas emissions and soil indicators four years after manure and compost applications. Journal of Environmental Quality. 32(1): 23-32. DOI: $10.2134 /$ jeq2003.2300

Guingand N., Quiniou N. \& Courboulay V. (2010). Comparison of ammonia and greenhouse gas emissions from fattening pigs kept either on partially slatted floor in cold conditions or on fully slatted floor in thermoneutral conditions. International Symposium on Air Quality and Manure Management for Agriculture Conference Proceedings, 13-16 September 2010, Dallas, Texas. American Society of Agricultural and Biological Engineers. 1. DOI: 10.13031/2013.32688

Hinh N. T. (2017). Research on the economic efficiency of biogas plants to explain the behavior of households in biogas invesment. Journal of Agriculture and Rural Development. 18(2): 5 -11 (in Vietnamese)

Hutchinson G. \& Livingston G. (1993). Use of chamber systems to measure trace gas fluxes. Agricultural ecosystem effects on trace gases and global climate change. 55: 63-78. DOI: 10.2134/asaspecpub55.c4.

Hutchinson G. \& Mosier A. (1981). Improved soil cover method for field measurement of nitrous oxide fluxes. Soil Science Society of America Journal. 45(2): 311316.

DOI:

10.2136/sssaj1981.03615995004500020017x.
Korkut N. E., Yaman C., Küçükağa Y., Jaunich M. K., \& Demir İ. (2018). Greenhouse gas contribution of municipal solid waste collection: A case study in the city of Istanbul, Turkey. Waste Management \& Research. 36(2): 131-139. DOI: 10.1177/0734242X17744656.

Kusa K., Sawamoto T., Hu R. \& Hatano R. (2008). Comparison of the closed-chamber and gas concentration gradient methods for measurement of $\mathrm{CO} 2$ and $\mathrm{N} 2 \mathrm{O}$ fluxes in two upland field soils. Soil Science and Plant Nutrition. 54(5): 777-785. DOI: 10.1111/j.1747-0765.2008.00292.x

Misselbrook T., Laws J. \& Pain B. (1996). Surface application and shallow injection of cattle slurry on grassland: nitrogen losses, herbage yields and nitrogen recoveries. Grass and Forage Science. 51(3): 270-277. DOI: 10.1111/j.1365-2494.1996.tb02062.x.

Misselbrook T. \& Powell J. (2005). Influence of bedding material on ammonia emissions from cattle excreta. Journal of Dairy Science. 88(12): 4304-4312. DOI: 10.3168/jds.S0022-0302(05)73116-7.

Molino A., Nanna F., Ding Y., Bikson B. \& Braccio G. (2013). Biomethane production by anaerobic digestion of organic waste. Fuel. 103: 1003-1009. DOI: 10.1016/j.fuel.2012.07.070.

Müller C. (2007). Anaerobic digestion of biodegradable solid waste in low-and middle-income countries. Sandec report. Retrieved from https://www.eawag.ch/fileadmin/Domain1/Abteilung en/sandec/publikationen/SWM/Anaerobic_Digestion/ biowaste.pdf on April 23, 2019.

Nguyen Van Bo (2017). Production situation and use of organic fertilizers from animal waste in Vietnam. Proceedings on investment policy solutions and financial mechanisms for efficient and sustainable livestock waste treatment. October 17-18, 2017. Ha Long City, Quang Ninh province (in Vietnamese).

Ngwabie N., Jeppsson K.-H., Gustafsson G. \& Nimmermark S. (2011). Effects of animal activity and air temperature on methane and ammonia emissions from a naturally ventilated building for dairy cows. Atmospheric Environment. 45(37): 6760-6768. DOI: 10.1016/j.biosystemseng.2019.03.012.

Philippe F.-X., Laitat M., Canart B., Vandenheede M. \& Nicks B. (2007). Comparison of ammonia and greenhouse gas emissions during the fattening of pigs, kept either on fully slatted floor or on deep litter. Livestock Science. 111(1-2): 144-152. DOI:10.1016/j.livsci.2006.12.012.

Philippe F.-X., Laitat M., Nicks B. \& Cabaraux J.-F. (2012). Ammonia and greenhouse gas emissions during the fattening of pigs kept on two types of straw floor. Agriculture, Ecosystems \& Environment. 150: 45-53. DOI: 10.1016/j.agee.2012.01.006.

Philippe F., Laitat M., Wavreille J., Nicks B. \& Cabaraux J. (2014). Effects of the amount of straw on ammonia 
and greenhouse gases emissions associated to fattening pigs kept on deep litter. Journées Rech. Porcine. 46: 213-214. DOI: 10.1016/j.agee.2014.08.015.

Phillips V., Scholtens R., Lee D., Garland J. \& Sneath R. (2000). A review of methods for measuring emission rates of ammonia from livestock buildings and slurry or manure stores, part 1: assessment of basic approaches. Journal of Agricultural Engineering Research. $\quad 77(4)$ : 355-364. DOI: 10.1006/jaer.2000.0613.

Roubík H., Mazancová J., Banout J. \& Verner V. (2016). Addressing problems at small-scale biogas plants: a case study from central Vietnam. Journal of Cleaner Production. 112: 2784-2792. DOI: 10.1016/j.jclepro.2015.09.114.

Sun G., Guo H. \& Peterson J. (2010). Seasonal odor, ammonia, hydrogen sulfide, and carbon dioxide concentrations and emissions from swine growerfinisher rooms. Journal of the Air and Waste Management Association. 60(4): 471-480. DOI: 10.3155/1047-3289.60.4.471.

Sun G., Guo H., Peterson J., Predicala B. \& Laguë C. (2008). Diurnal odor, ammonia, hydrogen sulfide, and carbon dioxide emission profiles of confined swine grower/finisher rooms. Journal of the Air \& Waste Management Association. 58(11): 1434-1448. DOI: 10.3155/1047-3289.58.11.1434.

Thu C. T. T., Cuong P. H., Van Chao N., Trach N. X. \& Sommer S. G. (2012). Manure management practices on biogas and non-biogas pig farms in developing countries-using livestock farms in Vietnam as an example. Journal of Cleaner Production. 27: 64-71. DOI: 10.1016/j.jclepro.2012.01.006.

Tong Xuan Chinh (2017). Current situation and solutions for livestock waste treatment. Evaluation of livestock waste treatment technology on smallholder farm scale. December $07^{\text {th }}, 2017$. Ho Chi Minh city [Online]. Retrieved from http://lcasp.org.vn/vi/news/hoi-thaodanh-gia-cong-nghe-xu-ly-chat-thai-chan-nuoi-quymo-trang-trai-351.html on January 19, 2020 (in Vietnamese).

Tran M., Vu T., Sommer S. G. \& Jensen L. S. (2011). Nitrogen turnover and loss during storage of slurry and composting of solid manure under typical Vietnamese farming conditions. The Journal of Agricultural
Science. 149(3): 285.2 DOI: $10.1017 /$ S0021859610000699.

USAID (2012). Greenhouse Gas Emissions Factsheet: Vietnam. The United States Agency for International Development [Online]. Retrieved from https://www.climatelinks.org/sites/default/files/as set/document/Vietnam\%20Fact $\% 20$ Sheet $\% 20$ \%20rev\%2010\%2007\%2016_Final.pdf on April $25,2019$.

Whalen S. \& Reeburgh W. (2001). Carbon monoxide consumption in upland boreal forest soils. Soil Biology and Biochemistry. 33(10): 1329-1338. DOI: 10.1016/S0038-0717(01)00038-4.

Yaman C. (2020). Application of Sterilization Process for Inactivation of Bacillus Stearothermophilus in Biomedical Waste and Associated Greenhouse Gas Emissions. Applied Sciences. 10(15): 5056. DOI: 10.3390/app10155056.

Yaman C. (2020). Investigation of greenhouse gas emissions and energy recovery potential from municipal solid waste management practices. Environmental Development. 33: 100484. DOI: 10.1016/j.envdev.2019.100484.

Yaman C. (2020). Monitoring of Biochemical Parameters and GHG Emissions in Bioaugmented Manure Composting. Processes. 8(6): 681. DOI: 10.3390/pr8060681.

Yaman C., Anil I., \& Alagha O. (2020). Potential for greenhouse gas reduction and energy recovery from MSW through different waste management technologies. Journal of Cleaner Production. 264: 121432. DOI: 10.1016/j.jclepro.2020.121432.

Yaman C., Anil I., Jaunich M. K., Blaisi N. I., Alagha O., Yaman A. B., \& Gunday S. T. (2019). Investigation and modelling of greenhouse gas emissions resulting from waste collection and transport activities. Waste Management \& Research. 37(12): 1282-1290. DOI: $10.1177 / 0734242 X 19882482$.

Yılmaz İ. H. \& Abdulvahitoğlu A. (2019). Evaluation of municipal solid waste options in Turkey: Scenarios for energy recovery, carbon mitigation and consequent financial strategies. Resources, Conservation and Recycling. 147 : 95-110. DOI: 10.1016/j.resconrec.2019.02.029. 